\title{
Patterns of Failure after Postoperative Radiation Therapy for Endometrial Carcinoma
}

Suzy Kim, M.D., M.S. ${ }^{1}$, Hong-Gyun Wu, M.D., Ph.D. ${ }^{2,3,4}$, Hyo-Pyo Lee, M.D., Ph.D. ${ }^{3,5}$, Soon-Beom Kang, M.D., Ph.D. ${ }^{3,5}$, Yong-Sang Song, M.D., Ph.D. ${ }^{3,5}$, Noh-Hyun Park, M.D., Ph.D., and Sung Whan Ha, M.D., Ph.D. ${ }^{2,3,4}$

${ }^{1}$ Department of Radiation Oncology, The Catholic University of Korea College of Medicine, ${ }^{2}$ Department of Radiation Oncology, Seoul National University College of Medicine, ${ }^{3}$ Cancer Research Institute, Seoul National University College of Medicine, ${ }^{4}$ Institute of Radiation Medicine, Medical Research Center, Seoul National University, 5Department of Obstetrics and Gynecology, Seoul National University College of Medicine, Seoul, Korea

Purpose: We tried to investigate the outcome and patterns of failure of endometrial cancer patients who were treated with surgery and postoperative radiation therapy (RT).

Materials and Methods: Eighty-three patients with endometrial cancer who received postoperative RT between May 1979 and August 2000 were included in this retrospective study. Forty-one patients received total abdominal hysterectomy, 41 patients received Wertheim's operation and 1 underwent vaginal hysterectomy. Pelvic lymph node dissection or pelvic lymph node sampling was done in $\mathbf{5 6}$ patients and peritoneal cytology was done in 35. All the patients were staged according to 1988 FIGO (International Federation of Gynecology and Obstetrics) staging system; 2 were stage IA, 23 were stage IB, 20 were stage IC, 4 were stage IIA, 5 were stage IIB, 9 were stage IIIA, 2 were stage IIIB and 18 were stage IIIC. The histologic diagnoses were adenocarcinoma in seventy-four patients $(89 \%)$. The histologic grades were Grade 1, 2 and 3 in 21 (25\%), 43 (52\%) and $10(12 \%)$ patients, respectively. All the patients received external beam RT (EBRT) with a median dose of 5,040 cGy (range: $4,500 \sim 5,075 \mathrm{CGy})$ to the whole pelvis. Five patients with pathologically confirmed paraaortic lymph node metastasis received $4500 \mathrm{cGy}$ to the paraaortic lymph nodes. Fifteen patients received low-dose intracavitary brachytherapy after their EBRT. A total dose of 7,500 9,540 cGy (median dose: 8511) was prescribed to the vaginal surface.
Results: Overall, 11 patients (13\%) experienced disease relapse: 4 with initial stage I or II disease and 7 with initial stage III disease. Among the 54 stage I or II patients, 1 $(2 \%)$ relapsed in the pelvis only, $2(4 \%)$ relapsed in the vagina and distant organs, and $1(2 \%)$ relapsed in the paraaortic lymph nodes (PANs). Among the 29 stage III patients, $1(3 \%)$ relapsed in the vagina. The most common sites of failure for the stage III patients were the peritoneum (3 patients, 10\%), PANs (2 patients, 7\%), and lung (2 patients, 7\%). With a median follow-up period of 86 months, the overall survival (OS) and disease-free survival (DFS) rates at 5 years were $87 \%$ for both. The five-year DFS rate was $93 \%, 100 \%$ and $74 \%$ for the stage I, II and III patients, respectively. Three patients experienced severe radiation-related late complications: RTOG (Radiation Therapy Oncology Group) grade 3 radiation cystitis was seen in one patient, and grade 3 bowel obstruction was seen in two patients.

Conclusions: Postoperative RT was useful for controlling pelvic disease. The major patterns of failure for stage III patients were peritoneal seeding and distant metastasis. Selective use of whole abdominal radiotherapy or adjuvant chemotherapy may improve the therapeutic outcome of these patients. (Cancer Res Treat. 2006;38: 133-138)

Key Words: Endometrial neoplasms, Postoperative radiation therapy, Patterns of failure
Correspondence: Hong-Gyun Wu, Department of Radiation Oncology, Seoul National University College of Medicine, 28, Yeongeondong, Jongno-gu, Seoul 110-744, Korea. (Tel) 82-2-2072-3177, (Fax) 82-2-765-3317, (E-mail) wuhg@snu.ac.kr

Received December 22, 2005, Accepted March 20, 2006

\footnotetext{
INTRODUCTION

Endometrial cancer is the most common gynecologic malignancy in the United States and it's the fourth most common cancer of women (1). According to a recent report, the incidence of endometrial cancer is increasing annually in Korea (2). Its age-adjusted incidence rate has increased from 1.32 per 100,000 women in 1993 to 2.64 in 2002. Before 1997, this
} 
malady was most commonly seen in women of the seventh decade, but now it is most common in women of the sixth decade.

Most cases of endometrial cancer are diagnosed at FIGO stage I or II. In Korea, stage I comprised $63.6 \%$ of all the endometrial cancer cases in the year 2002 (2). The standard treatment for stage I, II and III endometrial cancer is surgery, and then postoperative RT is offered to the patients who are at high risk for disease recurrence. This retrospective study analyzed the outcome and patterns of failure of the patients who have received surgery and postoperative RT for endometrial cancer during the past 20 years at Seoul National University Hospital (SNUH).

\section{MATERIALS AND METHODS}

We reviewed the medical records of 83 patients who were suffering with stage I, II and III endometrial cancer and who were treated with surgery and postoperative RT at SNUH between May 1979 and August 2000. The inclusion criteria were as follows: (i) a total radiation dose $\geq 45 \mathrm{~Gy}$, (ii) no previous or synchronous malignancy, (iii) no distant metastasis, and (iv) a follow-up period of more than 24 months. The median age of the patients was 56 years (range: 30 77). Information about the patients' menopause state, parity and combined medical illness (hypertension or diabetes mellitus) were not available for all patients. The clinical characteristics

Table 1. Patient characteristics

\begin{tabular}{lc}
\hline \multicolumn{1}{c}{ Characteristics } & No. of patients (\%) \\
\hline Menopause status & \\
$\quad$ Pre-menopause & $12 / 83(14 \%)$ \\
Post-menopause & $45 / 83(54 \%)$ \\
$\quad$ Median age at menopause (in years) & 50 \\
Nulliparity & $6 / 62(10 \%)$ \\
Combined illness & \\
Obesity & $26 / 55(47 \%)$ \\
Hypertension & $13 / 61(21 \%)$ \\
Diabetes mellitus & $9 / 61(15 \%)$ \\
\hline
\end{tabular}

of the patients are listed in Table 1.

All the patients received hysterectomy. Forty-one patients received total abdominal hysterectomy, 41 received Wertheim's operation and 1 received vaginal hysterectomy. The histologic diagnoses were adenocarcinoma in 75 patients, adenosquamous cell carcinoma in 6 and adenoacanthoma in 2 patients. Fiftyfour patients underwent pelvic lymph node dissection and two patients underwent pelvic lymph node sampling. Five patients underwent PAN sampling because they were suspected to have PAN metastasis on the preoperative computed tomography scan and this was pathologically confirmed in all cases. In 1989, standard surgical staging for endometrial cancer was introduced by the FIGO Committee on Gynecological Oncology (3). Therefore, peritoneal cytology examination was done for $18 \%(6 / 33)$ of our cases before 1990. But from 1990 on, 58\% (29/50) of the cases were evaluated for peritoneal cytology. Four out of the 35 cases were positive for malignant cells.

All patients were staged according to the 1988 FIGO staging system. The proportion of FIGO Stage I, II and III was 54\%, $11 \%$ and $35 \%$. The distribution of the pathologic stage and grade is shown in Table 2.

Postoperative RT was administered within $3 \sim 8$ weeks following surgery. All the patients received EBRT to the whole pelvis with using the four-field box technique. The superior border was specified at the L5-S1 disc and the inferior border at the bottom of the obturator foramina. The lateral borders are set 1.5 to $2.0 \mathrm{~cm}$ beyond the edge of the pelvic rim. The total dose was 4,500 5,075 cGy with a daily dose of $175 \sim 200$ cGy. Five patients who had pathologically confirmed PAN metastasis received 4,500 cGy to the paraaortic lymph nodes with a daily fraction of $180 \mathrm{cGy}$. One stage IIIC patient with peritoneal seeding was treated with parallel opposed fields to the whole abdomen and pelvis with total dose of 3,000 cGy in 20 fractions. After whole abdominal irradiation, the paraaortic field and pelvis were boosted to a midplane dose of 4,620 cGy and 5,520 cGy, respectively. The fifteen patients treated before 1989 received a vaginal boost with brachytherapy following EBRT. The vaginal brachytherapy consisted of using Manchester ovoids. 3,000 4,500 cGy was delivered to the vaginal surface with a dose rate of $50 \sim 70 \mathrm{cGy} / \mathrm{hr}$. The total dose prescribed to the vaginal surface was 7,500 9,540 cGy (median dose: 8,511 cGy).

Adjuvant chemotherapy was not routinely performed for the endometrial cancer patients; however, two patients of our study

Table 2. Pathologic distribution of disease

\begin{tabular}{|c|c|c|c|c|c|c|c|c|c|}
\hline & \multicolumn{3}{|c|}{ Stage I } & \multicolumn{2}{|c|}{ Stage II } & \multicolumn{3}{|c|}{ Stage III } & \multirow{2}{*}{ Total } \\
\hline & IA & IB & IC & IIA & IIB & IIIA & IIIB & IIIC & \\
\hline Grade 1 & 2 & 6 & 1 & 3 & 2 & 4 & 0 & 3 & 21 \\
\hline Grade 2 & 0 & 11 & 12 & 1 & 3 & 2 & 2 & 12 & 43 \\
\hline Grade 3 & 0 & 3 & 5 & 0 & 0 & 2 & 0 & 0 & 10 \\
\hline Unknown & 0 & 3 & 2 & 0 & 0 & 1 & 0 & 3 & 9 \\
\hline Total & & 45 & & & & & 29 & & 83 \\
\hline
\end{tabular}


population received three cycles of postoperative combination chemotherapy with cisplatin, adriamycin (or epirubicin) and cyclophosphamide.

The overall survival (OS) and disease-free survival (DFS), as well as the freedom from pelvic recurrence (FPR) rates, were calculated using the Kaplan-Meier method (4). Log rank statistics were used for the comparing the prognostic variables (5). Multivariate analysis using Cox regression analysis was also performed (6). The acute and late radiation-related toxicities were evaluated using the RTOG criteria (7).

\section{RESULTS}

\section{1) Patterns of failure}

The patterns of failure are shown in Table 3. Altogether, eleven patients $(13 \%)$ experienced disease recurrences. The

Table 3. Patterns of failure

\begin{tabular}{lcc}
\hline \multirow{2}{*}{ Site of failure } & \multicolumn{2}{c}{ No. of patients $(\%)$} \\
\cline { 2 - 3 } & Stage I or II & Stage III \\
\hline Pelvis only & & \\
$\quad$ Vagina & 0 & $1(3 \%)$ \\
Other than vagina & $1(2 \%)$ & 0 \\
Extrapelvic sites & $1(2 \%)$ & 0 \\
PAN & & $1(3 \%)$ \\
PAN+peritoneal seeding & 0 & $1(3 \%)$ \\
PAN+DM & 0 & $2(7 \%)$ \\
Peritoneal seeding & 0 & $2(7 \%)$ \\
DM & 0 & 0 \\
Pelvis+extrapelvic sites & $2(4 \%)$ & \\
Vagina+DM &
\end{tabular}

*paraaortic lymph node, ${ }^{\dagger}$ distant metastasis. median time to recurrences was 7 months (range: 3 91 months) from the date of surgery.

Among the fifty-four patients with stage I or II disease, one patient was found to have vaginal recurrence and liver metastasis simultaneously at 4 months after the surgery, and another patient was found to have supraclavicular lymph node metastasis and vaginal recurrence at 7 years after the surgery. There was an additional patient who relapsed at other intrapelvic site 8 months after the original surgery. The FPR rate at 5 years was $96 \%$ for all the stage I and II patients.

Among the fifty-four patients with stage I or II disease, there were twenty-one patients with stage IA or IB and grade 1 or 2 disease. Excluding these relatively low-risk patients, the 5-year FPR rate was $94 \%$.

Among the twenty-nine stage III patients, one relapsed in the vagina. The most common sites of relapse were peritoneum (3 patients), PAN (2 patients) and lung ( 2 patients). Table 4 summarizes the clinicopathologic characteristics of the 11 recurrent cases.

No vaginal recurrence developed in the group of patients who received intracavitary vaginal cuff irradiation, including the two patients who demonstrated microscopically positive vaginal resection margins. On the other hand, three vaginal recurrences developed among the 68 patients who had not received brachytherapy.

\section{2) The overall and disease-free survival rates}

The median follow-up time was 86 months (range: 5 268 months). The OS and DFS rates at 5 years were both $87 \%$.

The five-year OS, according to the stage, was $91 \%, 100 \%$ and $78 \%$ for stage I, II and III disease, respectively. The five-year DFS rate of stage I, II and III patients was $93 \%$, $100 \%$ and $74 \%$, respectively. The OS and DFS curves with using the Kaplan-Meier method are shown in Fig. 1 and 2. By the $\log$ rank test, the DFS of stage I and II patients was significantly higher than that of the stage III patients ( $94 \%$ vs. $74 \%$, respectively, at 5 years, $\mathrm{p}=0.02$ ). Yet the difference between the OS of stage I and II patients and that of stage III

Table 4. Clinicopathologic characteristics of the recurrent cases

\begin{tabular}{|c|c|c|c|c|c|c|c|c|c|}
\hline Case & Age & Stage & Grade & $\begin{array}{l}\text { Depth of } \\
\text { myometrial } \\
\text { invasion }\end{array}$ & $\begin{array}{c}\text { Brachytherapy } \\
\text { boost }\end{array}$ & $\begin{array}{l}\text { Site of } \\
\text { recurrence }\end{array}$ & $\begin{array}{l}\text { Time to } \\
\text { recurrence }\end{array}$ & $\begin{array}{c}\text { Recurrence } \\
\text { treatment } \\
\text { (months) }\end{array}$ & $\begin{array}{l}\text { Outcome } \\
\text { (months) }\end{array}$ \\
\hline 1 & 33 & IB & 3 & $<1 / 2$ & No & Vagina, liver & 3 & Chemo & DOD*: 11 \\
\hline 2 & 57 & IC & 2 & $>1 / 2$ & No & $\mathrm{SCL}^{\dagger}$, vagina & 91,112 & Chemo & DOD: 128 \\
\hline 3 & 50 & IC & NA & $>1 / 2$ & No & $\operatorname{PAN}^{\ddagger}$ & 7 & Surgery & DOD: 7 \\
\hline 4 & 66 & IIB & 2 & $<1 / 2$ & No & Pelvis & 8 & $\mathrm{NA}^{\S}$ & DOD: 20 \\
\hline 5 & 30 & IIIA & 1 & $>1 / 2$ & Yes & Chest wall, liver, lung & 59 & Hormonal therapy & DOD: 76 \\
\hline 6 & 65 & IIIA & 2 & $>1 / 2$ & No & Vagina & 5 & Hormonal therapy & DOD: 13 \\
\hline 7 & 54 & IIIB & 2 & $>1 / 2$ & Yes & PAN, peritoneum & 3 & None & DOD: 5 \\
\hline 8 & 59 & IIIC & 1 & $>1 / 2$ & No & Cervical lymph node & 27 & Hormonal therapy & DOD: 45 \\
\hline 9 & 69 & IIIC & 2 & $>1 / 2$ & No & PAN, lung & 5,7 & None & DOD: 10 \\
\hline 10 & 51 & IIIC & 1 & $>1 / 2$ & Yes & Peritoneum & 6 & None & DOD: 6 \\
\hline 11 & 61 & IIIC & 2 & $<1 / 2$ & Yes & Peritoneum & 12 & None & DOD: 14 \\
\hline
\end{tabular}

*dead of disease, ${ }^{\dagger}$ supraclavicular lymph nodes, ${ }^{*}$ paraaortic lymph nodes, ${ }^{\S}$ not available. 


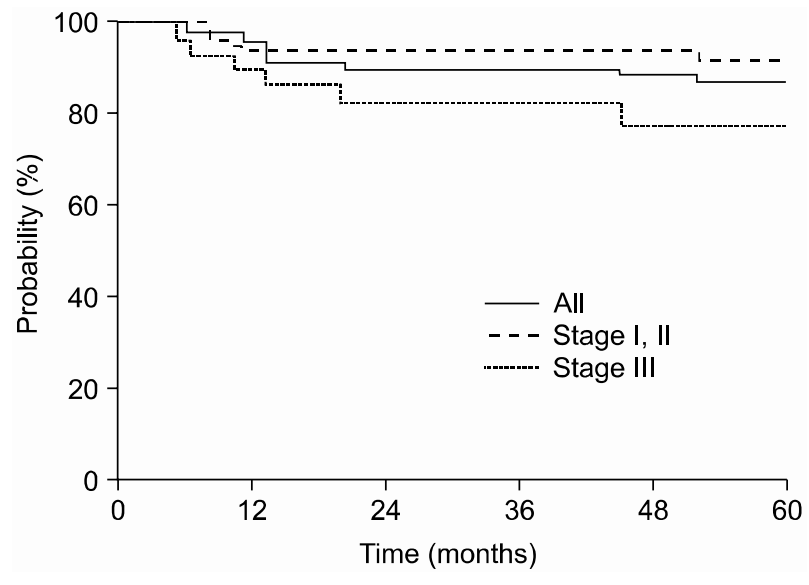

Fig. 1. Overall survival curves using the Kaplan-Meier method.

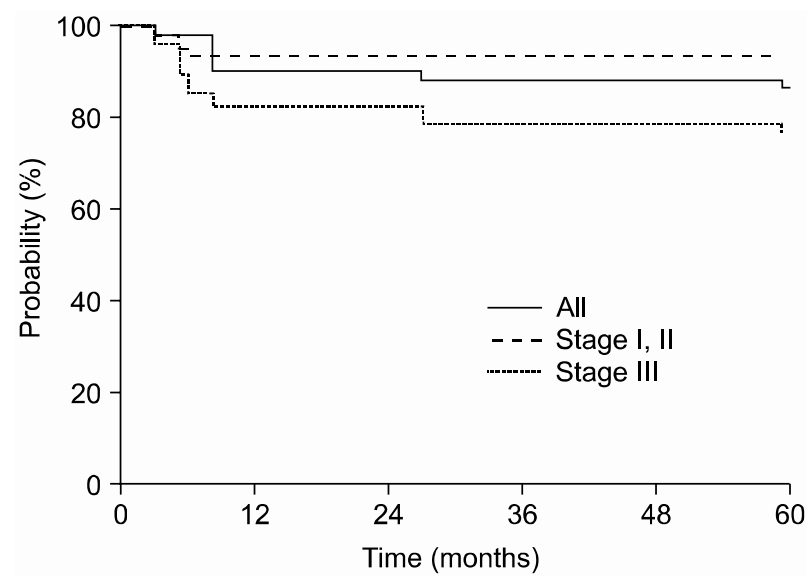

Fig. 2. Disease-free survival curves using the Kaplan-Meier method.

patients didn't reached statistical significance ( $92 \%$ vs. $78 \%$, respectively, at 5 years, $\mathrm{p}=0.10$ ).

\section{3) Prognostic factors for OS and DFS}

The prognostic variables evaluated for the univariate analysis included age ( $\leq 65$ vs. $>65$ ), stage (stage I and II vs. stage III), grade (1 and 2 vs. 3$)$, depth of myometrial invasion $(\leq 1 / 2$ of the myometrial thickness vs. $>1 / 2$ of the myometrial thickness), the presence of cervical stromal invasion, the presence of parametrial invasion, lymph node metastasis (no vs. yes) and the use of brachytherapy (no vs. yes). The univariate analysis of prognostic variables for OS and DFS is shown in Table 5. Age $(\mathrm{p}=0.003)$ and the depth of myometrial invasion $(p=0.01)$ were significant factors for OS. For DFS, the stage $(p=0.02)$ and depth of myometrial invasion $(p=0.04)$ were statistically significant.

The variables included in the multivariate analysis were age, stage, depth of myometrial invasion and the presence of parametrial invasion (Table 6). In this analysis, an older age ( $>65$ years old) and the presence of more than 1/2 depth of myometrial invasion were determined to be poor prognostic factors for OS ( $\mathrm{p}=0.02$ and 0.04 , respectively). For DFS, the
Table 5. Univariate analysis for overall survival and disease free survival

\begin{tabular}{|c|c|c|c|c|c|}
\hline \multirow{2}{*}{$\begin{array}{l}\text { Prognostic } \\
\text { factors }\end{array}$} & & $5-y$ & & $5-\mathrm{y}$ & \\
\hline & Groupings & $\begin{array}{l}\text { OS } \\
(\%)\end{array}$ & p-value & $\begin{array}{l}\text { DFS } \\
(\%)\end{array}$ & p-value \\
\hline Age & $\begin{array}{l}\leq 65 \\
>65\end{array}$ & $\begin{array}{l}90 \\
73\end{array}$ & 0.003 & $\begin{array}{l}88 \\
83\end{array}$ & 0.23 \\
\hline Stage & $\begin{array}{l}\text { I, II } \\
\text { III }\end{array}$ & $\begin{array}{l}92 \\
78\end{array}$ & 0.10 & $\begin{array}{l}94 \\
74\end{array}$ & 0.02 \\
\hline Grade & $\begin{array}{l}1,2 \\
3\end{array}$ & $\begin{array}{l}89 \\
75\end{array}$ & 0.72 & $\begin{array}{l}87 \\
90\end{array}$ & 0.78 \\
\hline $\begin{array}{l}\text { Depth of myometrial } \\
\text { invasion }\end{array}$ & $\begin{array}{l}\text { None or } \\
\leq 1 / 2 \\
>1 / 2\end{array}$ & 94 & 0.01 & 94 & 0.04 \\
\hline Cervical stromal inva & rasion & & & & \\
\hline & $\begin{array}{l}\text { No } \\
\text { Yes }\end{array}$ & $\begin{array}{l}89 \\
81\end{array}$ & 0.45 & $\begin{array}{l}89 \\
81\end{array}$ & 0.33 \\
\hline Parametrial invasion & $\begin{array}{l}\text { No } \\
\text { Yes }\end{array}$ & $\begin{array}{l}89 \\
82\end{array}$ & 0.13 & $\begin{array}{l}91 \\
73\end{array}$ & 0.11 \\
\hline Lymph node metasta & $\begin{array}{l}\text { asis } \\
\text { No } \\
\text { Yes }\end{array}$ & $\begin{array}{l}91 \\
79\end{array}$ & 0.33 & $\begin{array}{l}95 \\
79\end{array}$ & 0.10 \\
\hline Brachytherapy boost & $\begin{array}{l}\text { No } \\
\text { Yes }\end{array}$ & $\begin{array}{l}87 \\
87\end{array}$ & 0.93 & $\begin{array}{l}90 \\
80\end{array}$ & 0.49 \\
\hline
\end{tabular}

presence of more than $1 / 2$ depth of myometrial invasion was the only significant variable for a poor DFS $(p=0.03)$.

\section{4) Complications}

The acute toxicities were all RTOG Grade 0,1 or 2 . Leukocytopenia $(61 \%)$ was the most common hematologic toxicity. The frequent nonhematologic toxicities were abdominal pain (38\%), stool frequency (35\%) and nausea/vomiting (33\%).

The overall RTOG grade 3 and 4 late complication rate was $4 \%$ (3 out of 83). There was one case of grade 3 radiation cystitis. Grade 3 small bowel obstruction developed in two patients, and one of these patients had received 45 Gy RT to the paraaortic field.

\section{DISCUSSION}

There have been controversies regarding the benefit of performing postoperative pelvic RT for FIGO stage I or II endometrial cancer. Yet the recently published large-scale randomized trials have demonstrated that postoperative pelvic RT decreases the incidence of pelvic recurrences, but it did not affects overall survival $(8,9)$. In the GOG (Gynecologic Oncology Group) -99 study, 449 patients with stage IB to IIB endometrial adenocarcinoma with any grade were randomized after surgery to either the no additional therapy (NAT) group or the whole pelvic RT group. The estimated 2-year cumulative 
Table 6. Multivariate analysis for overall survival and disease free survival

\begin{tabular}{|c|c|c|c|c|}
\hline \multirow{2}{*}{ Variables } & \multicolumn{2}{|l|}{ OS } & \multicolumn{2}{|l|}{ DFS } \\
\hline & $\begin{array}{l}\text { Risk ratio } \\
(95 \% \text { C.I.*) }\end{array}$ & p-value & $\begin{array}{l}\text { Risk ratio } \\
(95 \% \text { C.I. })\end{array}$ & p-value \\
\hline Age $(\leq 65$ vs. $>65)$ & $\begin{array}{c}3.357 \\
(1.194 \sim 9.440)\end{array}$ & 0.02 & $\begin{array}{c}0.88 \\
(0.180 \sim 4.296)\end{array}$ & 0.87 \\
\hline Stage (I, II vs. III) & $\begin{array}{c}1.276 \\
(0.370 \sim 4.403)\end{array}$ & 0.7 & $\begin{array}{c}3.16 \\
(0.710 \sim 14.061)\end{array}$ & 0.13 \\
\hline $\begin{array}{l}\text { Myometrial invasion } \\
\text { (none or } \leq 1 / 2 \text { vs. } \\
>1 / 2 \text { ) }\end{array}$ & $\begin{array}{c}2.018 \\
(1.022 \sim 3.986)\end{array}$ & 0.04 & $\begin{array}{c}3.24 \\
(1.115 \sim 9.413)\end{array}$ & 0.03 \\
\hline $\begin{array}{l}\text { Parametrial invasion } \\
\text { (no. vs. yes) }\end{array}$ & $\begin{array}{c}1.319 \\
(0.331 \sim 5.251)\end{array}$ & 0.69 & $\begin{array}{c}0.58 \\
(0.107 \sim 3.158)\end{array}$ & 0.53 \\
\hline
\end{tabular}

*confidence interval.

incidence of recurrence was $12 \%$ in the NAT arm and $3 \%$ in the RT arm (relative hazard $(\mathrm{RH}): 0.42 ; \mathrm{p}=0.007)$. The estimated 4-year survival rate was $86 \%$ in the NAT arm and $92 \%$ for the RT arm. (RH: 0.86, p=0.557). In the PORTEC (Post Operative Radiation Therapy in Endometrial Carcinoma) study, 714 stage I patients, excluding those patients with stage IC, grade 3 or stage IB disease and grade 1 lesions, were randomized to the postoperative RT group or the no further treatment group. After long-term follow-up and a centralized pathology review, the 10-year locoregional relapse rates were $5 \%$ (for the RT group) and $14 \%$ (for the controls; $\mathrm{p}<0.0001$ ), and the 10 -year overall survival rates were $66 \%$ and $73 \%$, respectively $(\mathrm{p}=0.09)$.

In the present study, stage I or II patients comprised about two-thirds of the study population and their 5-year OS rate was $92 \%$. This overall survival rate is comparable with that of the RT arm in the randomized trials.

The five-year FPR and DFS rates of $96 \%$ and $94 \%$, respectively, for the stage I and II patients of our study are better than those of the previous reports. Yet we included those patients with grade 1 or 2 disease and who also had invasion of less than $1 / 2$ depth of the myometrial thickness. The five-year DFS and pelvic failure rates for these patients are reported to range from $90 \sim 95 \%$ and $0 \sim 5 \%$, respectively, even without adjuvant RT $(10 \sim 12)$. When excluding these 'lowrisk' patients, the 5-year FPR and DFS rates of the stage I and II patients in our study were still over $90 \%$ (94\% and $91 \%$, respectively). We can suppose that the postoperative RT lowered the pelvic recurrence rate of the high-risk patients to the level of that of the low-risk patients.

Since 1988 at SNUH, postoperative RT hasn't been for the stage I endometrial cancer patients having grade 1 or 2 disease with invasion of $<1 / 2$ of the myometrial thickness. Recently, a vaginal brachytherapy boost has also not been indicated for endometrial cancer patients unless their surgical resection margins were positive for malignant cells.
The benefit of the brachytherapy vaginal cuff boost is controversial. Bliss and Cowie have retrospectively analyzed 91 endometrial cancer patients who received postoperative RT according to whether or not they received any additional intracavitary brachytherapy (13). Although the group receiving additional brachytherapy had more patients with poor prognostic factors, no vaginal vault recurrence was observed in that group. But a $10 \%$ (four out of forty patients) vaginal vault recurrence rate was observed in the group that received external beam therapy alone. Greven et al, have compared the 5-year pelvic control and DFS rates of the external beam RT alone group (Group A) with those of the external beam RT with brachytherapy boost group (Group B) (14). No difference was detected for the 5-year pelvic control and DFS rates between groups $\mathrm{A}$ and $\mathrm{B}$.

In our study, only $18 \%$ of the patients received a brachytherapy boost and no vaginal recurrence was found in this group of patients. Although three vaginal vault recurrences were observed in the 68 patients who had not received brachytherapy boost, the differences of the FPR and DFS rates between the two groups were not statistically significant. Because the small number of patients in the group that received a brachytherapy boost, we cannot reach any conclusions regarding the benefit of brachytherapy boost.

For the stage III endometrial cancer patients in this study, the major patterns of failure were peritoneal seeding and distant metastases. PAN metastasis was frequently accompanied in these patients. Accordingly, the extrapelvic recurrence rate of the stage III patients was about $20 \%$. More efforts need to be made to decrease the extrapelvic recurrence rate, and this may well prolong the survival of this patient group.

The GOG (Gynecologists Oncology Group) has recently reported the outcome of performing adjuvant whole abdominal RT in the patients with stage III and IV endometrial cancer (15). Of the 180 evaluable patients who entered that study, 103 had high-risk histology, i.e., either papillary serous or clear cell cancers. They found that all the patients with gross residual disease after surgery eventually failed, even with whole abdominal RT, and this was regardless of the histologic type. They concluded that whole abdominal irradiation may improve the outcome of the patients with completely resected disease, but in their study, grade 3 and 4 gastrointestinal toxicity was observed in $11 \%$ and $4 \%$ of patients, respectively. Considering its higher risk of causing gastrointestinal complications compared with whole pelvis RT, further investigations for selecting the patients who may benefit from whole abdominal RT is required.

There are still limited published data on the potential benefit of administering adjuvant chemotherapy combined with adjuvant RT. The phase II trials have shown a response to chemotherapy for unresectable, recurrent or metastatic endometrial cancer. Doxorubicin, cisplatin and paclitaxel have all been shown to have activity as a single agent, with response rates of $20 \sim 35 \%(16 \sim 19)$. RTOG reported the preliminary analysis of postoperative RT combined with cisplatin/paclitaxel chemotherapy for the patients with high-risk endometrial cancer (20). $66 \%$ of the eligible patients had stage 111 disease. At the median follow-up of 28.7 months, the grade 3 and 4 chronic toxicities were $16 \%$ and $2 \%$, respectively. The pelvic recurrence, regional 
recurrence, distant recurrence, DFS and OS rates at 24 months were $2 \%, 3 \%, 17 \%, 83 \%$ and $90 \%$, respectively.

A phase III study (GOG122) randomized the patients with stage III and IV endometrial cancer to the whole abdominal irradiation group versus the chemotherapy with doxorubicin and cisplatin group. This study closed in February 2000 and its long-term results are being awaited. It will suggest some therapeutic guidelines for stage III and IV endometrial cancer.

Older age was a poor prognostic factor for OS, but not for DFS, in our study. This result is consistent with the result of a previous large cohort study (21). Deep myometrial invasion was the only significant prognostic factor for DFS in our study, but other pathologic factors such as stage, histologic grade, the peritoneal cytology, adnexal invasion, cervical extension, lymph node metastasis, the histologic type and lymph-vascular space invasion have been reported to be important prognostic factors in many other studies $(22 \sim 25)$. The efforts to identify the risk factors for recurrences may be helpful in establishing better treatment strategies.

\section{CONCLUSIONS}

Postoperative RT was useful for controlling pelvic disease in this study. The major patterns of failure for stage III patients were peritoneal seeding and distant metastasis. Selective use of a vaginal brachytherapy boost or whole abdominal RT may decrease the rate of intrapelvic or extrapelvic disease recurrence. Furthermore, the recent investigations conducted on adjuvant chemotherapy in combination with radiotherapy are anticipated to shed new light on how to improve the therapeutic outcome of the endometrial cancer patients with high risk factors.

\section{REFERENCES}

1. Jemal A, Murray T, Ward E, Samuels A, Tiwari RC, Ghafoor A, et al. Cancer statistics, 2005. CA Cancer J Clin. 2005; 55:10-30.

2. Lee SE, Kim JW, Par NH, Song YS, Kang SB, Lee HP. Contemporary trends of endometrial cancer in Korean women. Korean J Gynecol Oncol. 2005;16:215-20.

3. International Federation of Gynecology and Obstetrics. Corpus cancer staging. Int J Gynecol Obstet. 1989;28:190.

4. Kaplan EL, Meier P. Nonparametric estimation from incomplete observation. J Am Stat Assoc. 1958;53:457-81.

5. Mantel N. Evaluation of survival data and two new rank order statistics arising in its consideration. Cancer Chemother Rep. 1966;50:163-70.

6. Cox DR. Regression models and life tables. J R Stat Soc. 1972;34:187-220.

7. Herrmann T, Knorr A, Dorner K. The RTOG/EORTC classification criteria for early and late radiation reactions. Radiobiol Radiother (Berl). 1987;28:519-28.

8. Keys HM, Roberts JA, Brunetto VL, Zaino RJ, Spirtos NM, Bloss JD, et al. A phase III trial of surgery with or without adjunctive external pelvic radiation therapy in intermediate risk endometrial adenocarcinoma: a Gynecologic Oncology Group study. Gynecol Oncol. 2004;92:744-51.

9. Scholten AN, van Putten WL, Beerman H, Smit VT, Koper PC, Lybeert ML, et al. Postoperative radiotherapy for stage I endometrial carcinoma: long-term outcome of the randomized PORTEC trial with central pathology review. Int $\mathrm{J}$ Radiat Oncol Biol Phys. 2005;63:834-8.

10. Aalders J, Abeler V, Kolstad P, Onsrud M. Postoperative external irradiation and prognostic parameters in stage I endometrial carcinoma: clinical and histopathologic study of 540 patients. Obstet Gynecol. 1980;56:419-27.

11. Carey MS, O'Connell GJ, Johanson CR, Goodyear MD, Murphy KJ, Daya DM, et al. Good outcome associated with standardized treatment protocol using selective postoperative radiation in patients with clinical stage I adenocarcinoma of the endometrium. Gynecol Oncol. 1995;57:138-44.

12. Grigsby PW, Perez CA, Kuten A, Simpson JR, Garcia DM, Camel HM, et al. Clinical stage I endometrial cancer: prognostic factors for local control and distant metastasis and implications of the new FIGO surgical staging system. Int $\mathbf{J}$ Radiat Oncol Biol Phys. 1992;22:905-11.

13. Bliss P, Cowie VJ. Endometrial carcinoma: does the addition of intracavitary vault caesium to external beam therapy postoperatively result in improved control or increased morbidity? Clin Oncol (R Coll Radiol). 1992;4:373-6.

14. Greven KM, D'Agostino RB Jr, Lanciano RM, Corn BW. Is there a role for a brachytherapy vaginal cuff boost in the adjuvant management of patients with uterine-confined endometrial cancer? Int J Radiat Oncol Biol Phys. 1998;42:101-4.

15. Sutton G, Axelrod JH, Bundy BN, Roy T, Homesley HD, Malfetano $\mathrm{JH}$, et al. Whole abdominal radiotherapy in the adjuvant treatment of patients with stage III and IV endometrial cancer: a Gynecologic Oncology Group study. Gynecol Oncol. 2005;97:755-63.

16. Thigpen JT, Buchsbaum HJ, Mangan C, Blessing JA. Phase II trial of adriamycin in the treatment of advanced or recurrent endometrial carcinoma: a Gynecologic Oncology Group study. Cancer Treat Rep. 1979;63:21-7.

17. Thigpen JT, Blessing JA, Homesley H, Creasman WT, Sutton G. Phase II trial of cisplatin as first-line chemotherapy in patients with advanced or recurrent endometrial carcinoma: a Gynecologic Oncology Group study. Gynecol Oncol. 1989;33: 68-70.

18. Long HJ, Pfeifle DM, Wieand HS, Krook JE, Edmonson JH, Buckner JC. Phase II evaluation of carboplatin in advanced endometrial carcinoma. J Natl Cancer Inst. 1988;80:276-8.

19. Ball HG, Blessing JA, Lentz SS, Mutch DG. A phase II trial of paclitaxel in patients with advanced or recurrent adenocarcinoma of the endometrium: a Gynecologic Oncology Group study. Gynecol Oncol. 1996;62:278-81.

20. Greven K, Winter K, Underhill K, Fontenesci J, Cooper J, Burke T. Preliminary analysis of RTOG 9708: adjuvant postoperative radiotherapy combined with cisplatin/paclitaxel chemotherapy after surgery for patients with high-risk endometrial cancer. Int J Radiat Oncol Biol Phys. 2004;59:168-73.

21. Mundt AJ, Waggoner S, Yamada D, Rotmensch J, Connell PP. Age as a prognostic factor for recurrence in patients with endometrial carcinoma. Gynecol Oncol. 2000;79:79-85.

22. Mariani A, Webb MJ, Keeney GL, Calori G, Podratz KC. Hematogenous dissemination in corpus cancer. Gynecol Oncol. 2001;80:233-8.

23. Mariani A, Webb MJ, Keeney GL, Lesnik TG, Podratz KC. Surgical stage I endometrial cancer: predictors of distant failure and death. Gynecol Oncol. 2002;87:274-80.

24. Mariani A, Webb MJ, Keeney GL, Aletti G, Podratz KC. Predictors of lymphatic failure in endometrial cancer. Gynecol Oncol. 2002;84:437-42.

25. Mariani A, Webb MJ, Keeney GL, Aletti G, Podratz KC. Endometrial cancer: predictors of peritoneal failure. Gynecol Oncol. 2003;89:236-42. 